\title{
Teaching patients to recognise early symptoms of relapse reduced manic relapses and improved social functioning in bipolar disorder
}

\author{
Perry A, Tarrier N, Morriss R, et al. Randomised controlled trial of efficacy of teaching patients with bipolar disorder to identify \\ early symptoms of relapse and obtain treatment. BMJ 1999 Jan 16;318:149-53.
}

\section{Question}

In patients with bipolar disorder receiving routine care, is an education programme that trains patients to identify early symptoms of relapse effective in reducing manic and depressive relapses and improving social functioning?

\section{Design}

Randomised, single blind, controlled trial with 18 months of follow up.

\section{Setting}

3 NHS trusts in north west England.

\section{Patients}

69 patients who had a lifetime diagnosis of bipolar disorder, had had $\geqslant 2$ relapses with 1 in the previous 12 months, and were between 18 and 75 years of age (mean age 45 y, 69\% women). Exclusion criteria were inability to communicate in English, drug or alcohol abuse as a primary problem, or organic cerebral cause for bipolar disorder. Follow up was 99\% for relapse and $86 \%$ for social functioning.

\section{Intervention}

Patients were allocated to training plus routine care $(n=34)$ or routine care alone $(n=35)$. Patients in the training group collaborated with a research psychologist to learn to identify prodromal symptoms of manic or depressive relapse and to produce and rehearse an action plan once prodromes were recognised. Routine care consisted of drug treatment; monitoring of mood and adherence to treatment; support; education about bipolar disorder; and, if necessary, inpatient care.

\section{Main outcome measures}

Relapse ( $\geqslant 5 \mathrm{~d}$ of symptoms of mania, hypomania, mixed affective disorder, or depression), time to relapse, and overall social functioning by summing the scores on 8 areas measured using a 4 point scale.

\section{Main results}

Patients who received training plus routine care had a longer time to first manic relapse than those patients who received routine care alone (25th centile time to first relapse $65 v 17 \mathrm{wks}$, $\mathrm{p}=0.008$ ) but the groups did not differ for time to first depressive relapse (25th centile time to first depressive relapse 21 v 26 $w k s, p=0.19)$. At 18 months, fewer patients in the training group had manic relapses than the control group patients $(p=0.013)$; the groups did not differ for depressive relapses $(p=0.15)$ (table). Greater improvement in social functioning from baseline occurred in the training group than in the control group: the mean difference in change in social function score was 1.97 (95\% CI 0.7 to 3.23) and in employment score was 0.70 (CI 0.07 to 1.33$)$.

\section{Conclusion}

Training patients with bipolar disorder to recognise early symptoms of relapse reduced manic but not depressive relapses and improved social functioning.

Training plus routine care $v$ routine care alone in bipolar disorder at 18 months*

\begin{tabular}{lllll}
\hline Outcomes & $\begin{array}{l}\text { Training plus } \\
\text { routine care }\end{array}$ & $\begin{array}{l}\text { Routine } \\
\text { care alone }\end{array}$ & RRR (95\% CI) & NNT (CI) \\
\hline Manic relapse & $27 \%$ & $57 \%$ & $\begin{array}{l}52 \%(14 \text { to } 75) \\
\text { RRI (CI) }\end{array}$ & $\begin{array}{l}3 \text { (2 to 16) } \\
\text { NNH }\end{array}$ \\
$\begin{array}{c}\text { Depressive } \\
\text { relapse }\end{array}$ & $55 \%$ & $37 \%$ & $47 \%(-13$ to 154) & Not significant
\end{tabular}

*Abbreviations defined in glossary; RRR, RRI, NNT, NNH, and CI calculated from data in article.

Source of funding: North West Regional Health Authority.

For correspondence: Dr R Morriss, Department of Community Psychiatry, University of Manchester and Guild NHS Trust, Royal Preston Hospital, Preston PR2 9HT,UK. Fax +44 (0)1772 710772.

Abstract and commentary also published in Evidence-Based Medicine.

\section{Commentary}

This study by Perry et al shows that the addition of a training programme to teach patients to identify early symptoms of manic or depressive relapse in combination with an action plan once early symptoms had been recognised, increases time to a manic relapse. In contrast, it decreases time to a depressive relapse, although not significantly. As a result of this study, training can be considered an important element of a psychoeducational programme that should be offered to patients with bipolar disorder. A psycho-educational programme consists of several sessions in which patients (and sometimes their relatives) learn about the symptoms, causes, and treat- ment of the disorder; and may include written materials and video tapes. It has been shown that such programmes can result in better knowledge about the treatment and a decrease in level of expressed emotion. ${ }^{12}$ It should be noted, however, that without participating in a psycho-educational programme, many patients can learn about their disorder (and the early symptoms of relapses) from individual contact with their treating physician or from health consumer resources. ${ }^{3}$ It is possible therefore that the effect of a training and psycho-education programme depends on what patients already know of their disorder. As regards applicability, not all patients who might be eligible for a training and psychoeducational programme actually want to follow it (in this study, 69 of 179 eligible patients participated in the study).

Willem A Nolen, MD, PhD

University Medical Centre Utrecht and H C Rümke Group

Utrecht, the Netherlands

1 Peet M, Harvey NS. Lithium maintenance: 1. A standard education programme for patients. Br J Psychiatry 1991;158:197-200.

2 Honig A, Hofman A, Rozendaal N, et al. Psychoeducation in bipolar disorder: effect on expressed emotion. Psychiatry Res 1997;72:17-22.

3 Knoppert-van der Klein EAM, Hoogduin CAL, Van Peski-Oosterbaan AS, et al. Een standaard voorlichtinosprogramma voor de standaard voorlichtingsprogramma voor de lithiumbehandeling: een replicatieonderzoek.
Tijschiatr 1997;39:240-48. 